\title{
An Analysis of the Influence of QFII Shareholding Tendency on Stock Returns Volatility: from the Perspective of Industry Life Cycle
}

\author{
Siyu $\mathrm{Du}^{1, \mathrm{a}}$, Pan Xie $\mathrm{Xi}^{1,2, \mathrm{~b},{ }^{*}}$ \\ ${ }^{1}$ International Business School, Shaanxi Normal University, Xi'an, China \\ ${ }^{2}$ Center for Macroeconomic Research, Xiamen University, Xiamen, China \\ a0409ashley@snnu.edu.cn, bxiepan@snnu.edu.cn \\ ${ }^{*}$ Corresponding author
}

Keywords: QFII, Stock returns, Industry life cycle, GARCH family models.

\begin{abstract}
From the perspective of industry life cycle, we examine the influence of variations in QFII shareholding tendency on the stock returns volatility of 19 industries in Chinese A share market by establishing GARCH, TARCH and EGARCH models. The analysis results show that: (1) There is a significant asymmetry in the returns volatility of A-shares of listed companies in the construction, manufacturing and real estate industries. EGARCH model can better reveal the impact of QFII shareholding differences on the stock returns volatility; (2) Compared to industries that have transited from growth to maturity or recession, QFII is more likely to hold those stocks of the growing industries such as finance and real estate in long run; (3) After the fourth expansion, the stock price volatility of the construction and the real estate industries has dropped by 0.02 and 0.08 percentage points respectively compared with the third expansion, while the impact on the manufacturing industry is not significant.
\end{abstract}

\section{Introduction}

Since the Bank of Switzerland became the first Qualified Foreign Institutional Investors (QFII) on May 23, 2003, QFII has made considerable progress in China. By the end of October 2017, the number of domestic QFII institutions has grown by an average of 21 annually, and the total number of stocks (A-shares) exceeds 80 million shares. In the past fifteen years, with the opening-up of the financial industry, Chinese government regulators have adjusted the investment quota of foreign institutional investors more than once. In addition to the first 4 billion U.S. dollars investment quota for QFII on July 9, 2003, China Securities Regulatory Commission (CSRC) approved four new investment quotas for QFII investment institutions in 2005, 2007, 2012 and 2013, when the cumulative investment quotas have reached 10 billion, 30 billion, 80 billion and 150 billion U.S. dollars respectively. During the Boao Forum for Asia Annual Conference 2018, a series of financial industry reforms and opening measures were announced, indicating that more foreign institutions will participate in the construction of China's capital market in the future.

Will the implementation of the QFII system help to reduce stock price volatility, thereby setting up confidence for investors and stabilizing market expectations? Academics and industry circles are still controversial to such issue. Previous studies can be classified into the following three categories: The first category considers that allowing QFII shareholding has not caused stock market volatility. Dong Yi et al. use the QFII system as a policy event and compare the performance before and after the implementation of the event ${ }^{[1]}$. It is found that the QFII does not cause an increase in the volatility of China's A-share market. In contrast, the second category advocates that QFII shareholding aggravates the stock market volatility. Xu Nianxing et al. examine the impact of QFII on the stock price collapse risk at the company level ${ }^{[2]}$. From the perspective of institutional investors herd behavior, they find that the existence of QFII aggravates the positive relationship between herding behaviors and stock price synchronization. According to their research, institutional investors in China act as a "collapse accelerator" instead of "market stabilizer". The 
third category emphasizes the market's cyclical differences in shareholding effects. Rao Yulei et al. find that in bull markets, short-term QFII will significantly increase stock price synchronization; in bear markets, however, long-term QFII will obviously reduce synchronization ${ }^{[3]}$. The impact of QFII on stock price synchronization is significantly affected by the size of holding.

In the selection of analytical methods, many scholars have chosen the generalized autoregressive conditional heteroscedasticity $(\mathrm{GARCH})$ model or its variants. Liu Guoqi's first application of nonlinear GARCH model shows that the quadratic GARCH model (QGARCH) can predict the volatility of China's stock market well ${ }^{[4]}$. For many stocks, there is a strong negative correlation between current returns and future fluctuations. Therefore, under the premise that the residual sequence of the mean equation obeys normal distribution, the GARCH family models can describe the volatility of the Chinese stock market better. Taking social security funds and QFII funds as examples, Deng Xuebin applies asymmetric GARCH model to fit the changes in A-share returns, and examines the effect of institutional investors on the autocorrelation and volatility of stock index returns ${ }^{[5]}$. Zhao Yang further introduces the asymmetric factor into the TGARCH model, improving the fitting effect on the fluctuation of stock returns ${ }^{[6]}$.

However, the existing literature pays attention to the impact of QFII on the performance of the Shanghai Stock Index or Shenzhen Stock Index, but ignores effects discrepancy of QFII on diverse industries during different life cycle phases. To fill this gap, the innovation points of this paper are as follows: First, from the perspective of industry life cycle, we reveal QFII shareholding tendency variations in industries during different life cycles; Second, we adopt GARCH, TARCH and EGARCH models to capture asymmetric effects of QFII shareholding tendency on stock returns volatility, as well as possible influence mechanisms. Under the background of industrial transformation and upgrading, it is of great practical significance to explore approaches to expand the opening-up of the financial industry, balance risk prevention and industry progress.

\section{QFII shareholding tendency and industry life cycle demarcation}

\subsection{QFII shareholding tendency}

Based on the investment quota and market participation, we select the first implementation of the QFII system and the subsequent four quota expansions as symbolic events. The development process of QFII in China could be classified into the following five phases:

Table 1. Development phases of QFII in China

\begin{tabular}{ccc}
\hline Phase & Time & Symbolic events \\
\hline I & 2003.7.9-2005.7.11 & $\begin{array}{c}\text { The QFII system was piloted in China and the approved investment } \\
\text { quota was 4 billion U.S. dollars. The absolute increment of QFII and its } \\
\text { investment quotas during this period was very small; }\end{array}$ \\
\hline II & 2005.7.11-2007.12.9 & $\begin{array}{c}\text { The total quota increased to 10 billion U.S. dollars, and the QFII } \\
\text { shareholding ratio started to increase; }\end{array}$ \\
\hline III & $2007.12 .9-2012.4 .3$ & $\begin{array}{c}\text { The QFII quota increased from 10 billion to 30 billion U.S. dollars. } \\
\text { QFII was in rapid development in China in the following five years; }\end{array}$ \\
\hline IV & $2012.4 .3-2013.7 .12$ & $\begin{array}{c}\text { The QFII quota added 50 billion U.S. dollars and the total investment } \\
\text { quota reached 80 billion U.S. dollars; }\end{array}$ \\
\hline V & 2013.7.12 to now & $\begin{array}{c}\text { The total investment amount was further expanded to 150 billion U.S. } \\
\text { dollars, which would help attract more overseas long-term investment } \\
\text { institutions to enter the A-share market. }\end{array}$ \\
\hline
\end{tabular}

Source: According to relevant data of the State Administration of Foreign Exchange.

Compared to the subsequent two expansions, the expansion quota on December 9, 2007 is relatively small, so we combine the two expansion events on December 9, 2007 and April 3, 2012 to simplify the analysis. QFII shows a gradual increase in market value of shares of various industries. Among them, the average share proportion of financial industry was as high as $5.88 \%$, ranked first from 2006 to 2011, indicating that when banking industry has long been in the "era of 
interest margin", commonly foreign institutional investors have an optimistic view of Chinese financial market development. With the advancement of the interest rate marketization reform, the margin narrowed and the share proportion of financial industry gradually declined. According to threshold characterized by the highest share proportion no less than 3.50\%, QFII's major-held industries ranked in a descending order are: Financial industry, Water conservancy, environmental and public facilities management industry, Mining industry, Manufacturing industry, Leasing and business services industry, Hotel and catering industry, Construction industry, Real estate industry, Information transmission, software and information technology services industry.

\subsection{Industry life cycle demarcation}

We adopt the industry classification method proposed by Fan Conglai to classify the life cycle phases of QFII's major-held industries ${ }^{[7]}$. First, 2003-2017 years can be classified into four phases according to the expansion events, every two phases is considered as a group. Then, we calculate the growth rate of added value of each industry in two adjacent periods; Finally, we classify the industry's development phases by comparing calculated growth rate with annual average growth rate of real GDP in China over the same period. For example: (1) In the former and latter phases, if the average growth rate of the industry's added value is higher than that of GDP in the same phase, or if the former phase is lower than average GDP growth rate while the latter is higher, it is considered as a growing industry; (2) In the former phase, if the average growth rate is higher than that of GDP during the same period, and in the latter phase, average growth rate is lower than average GDP growth rate, such industry is defined as mature; (3) In the former and latter phases, if the average growth rate of the industry is lower than that of GDP in the corresponding phase, such industry is defined as recessionary. Considering the evolution of economic structure and the rise and development of the industry in the past 15 years, we consider 2003-2011 and 2012-2017 as two sub-phases, and obtain the cyclical characteristics of the two phases of various industries. The results show that the top nine major-held industries were all in the growth period from 2003 to 2011. QFII's major-held industries can be classified into the following three types according to the different life cycles between 2012 and 2017.

The first type of industry has been in growth period from 2003 to 2017, such as real estate industry and financial industry. Benefiting from the investment demand triggered by the round of urbanization process at the beginning of the new century, this type of industries enjoys a good growth rate, a high return on net assets and a considerable profit margin. Especially since 2012, with the contribution of value-added services to economic growth surpassing industry for the first time, the service industry, as an important support for stabilizing economic growth and employment, receive attention from foreign institutional investors continuously, information transmission, software and information technology services industry, scientific research and technology services industry and leasing and business services industry are typical ones. In addition, with people's disposable income growing steadily, listed companies in the areas of consuming upgrade such as hotel and catering industry, wholesale and retail industry have also been favored by foreign institutional investors.

The second type of industry is the construction industry that has transitioned from growth phase to maturity phase. As the costs of civil engineering and housing construction continue to rise, since 2012, under the influence of successive regulation policies of the real estate industry, the market demand growth of the construction industry has slowed down, and it has been hard to maintain long-term high profitability for related enterprises, and the stock price has often remained low. Therefore, the average share proportion of QFII for the construction industry in 2012-2017 has dropped to $0.90 \%$, which is a $12.50 \%$ decrease compared with $2003-2011$.

The third type of industry is an industry that has gradually entered recession from the growth phase. Due to the long-term lag in reform of resource product price formation mechanism and the high proportion of state-owned economy, the mining industry has a low degree of marketization and 
exist a serious mismatch between supply and demand. Hence, it is difficult to adapt to the needs of changes in production methods and business models, resulting in serious negative growth. Traditional manufacturing industries have also been restrained by overcapacity, what is worse, market demand has shrunk, net profit margins have fallen, thereby the dividend yield of related listed companies has been consistently lower than the market's average income level. As a result, the average shareholding ratio of QFII to the manufacturing industry falls drastically from $3.33 \%$ to $1.30 \%$ in 15 years, and it was only maintained in some well-developed equipment manufacturing industries.

Table 2. Types of major-held industries by QFII (2003-2017)

\begin{tabular}{cccl}
\hline Type & 2003-2011 & 2012-2017 & \multicolumn{1}{c}{ Industry } \\
\hline I & growth phase & growth phase & $\begin{array}{l}\text { Financial industry, Water conservancy, environmental and public } \\
\text { facilities management industry, Leasing and business services } \\
\text { industry, Hotel and catering industry, Real estate industry, } \\
\text { Information transmission, software and information technology } \\
\text { services industry }\end{array}$ \\
\hline II & growth phase & maturity phase & Construction industry \\
\hline III & growth phase & recession phase & Mining industry, Manufacturing industry \\
\hline
\end{tabular}

Because of the limited space, in the following parts, we select three representative business in each type of industry-real estate industry,-real estate industry, construction industry and manufacturing industry - for an analysis of the extent to which QFII's major holdings affect the volatility of stock returns, and compare various effects of QFII on diverse industries during different life cycle phases.

\section{Variable descriptions and data sources}

\subsection{Variable descriptions}

1. Industrial Index $\left(P_{t}\right)$. The volatility of the daily returns of industrial index can basically describe the volatility of the industry. Therefore, we select closing price of the first-tier industry index classified by the CSRC standards from April 2, 2001 to December 19, 2017 as the representation of industrial index. Data is from Wind database.

2. Industrial Index Volatility $\left(Y_{t}\right)$. Take the logarithm of the 4058 observations in the original industry index sequence $\left\{P_{t}\right\}$, and after the first-order difference, the index volatility sequence $\left\{Y_{t}\right\}$ can be obtained, $Y_{t}=\ln P_{t}-\ln P_{t-1}$.

3. Industrial trading volume $\left(v_{t}\right)$. Changes in industrial trading volume often have a direct impact on stock price volatility. We select the volume data of the first-tier industries according to the standard of CSRC from April 2, 2001 to December 19, 2017 as the representation of industrial trading volume. Data is from Wind database.

4. Industrial trading volume change rate $\left(V_{t}\right)$. The trading volume of QFII is relatively smaller than that of domestic institutional investors and individual investors. So we introduce the absolute increment of the logarithms of total trade volume as a control variable to the model, $V_{t}=\left|\ln v_{t}-\ln v_{t-1}\right|$.

5. Dummy variables $\left(D_{i}\right)$. According to the time point of the QFII expansion, we classify the 2003-2017 period into five periods and introduced four dummy variables to describe the QFII system events introduced in 2003, the first expansion event in 2005 and the third and the fourth expansion events in 2012 and 2013. 


$$
\begin{aligned}
& D_{1}=\left\{\begin{array}{ll}
1, & \text { After introducing QFII in } 2003 \\
0, & \text { Before introducing QFII in } 2003
\end{array} D_{2}= \begin{cases}1, & \text { After } 2005 \text { expansion event } \\
0, & \text { Before } 2005 \text { expansion event }\end{cases} \right. \\
& D_{3}=\left\{\begin{array}{ll}
1, & \text { After } 2012 \text { expansion event } \\
0, & \text { Before } 2012 \text { expansion event }
\end{array} \quad D_{4}= \begin{cases}1, & \text { After } 2013 \text { expansion event } \\
0, & \text { Before } 2013 \text { expansion event }\end{cases} \right.
\end{aligned}
$$

Taking the construction industry as an example, in the sample period, kurtosis of daily index return is 6.814 , higher than that of the normal distribution. The skewness is 0.421 , which shows the obvious left shift peak distribution, and indicates that the exponential volatility has an obvious peak and fat tail characteristic. The J-B statistic value is 2578.086 , and the $P$ value is very small, so the distribution of index return of the construction industry is significantly different from normal distribution. Descriptive statistical results of the main variables are shown in table 3:

Table 3. Descriptive statistical results of the main variables

\begin{tabular}{cccccc}
\hline Variable & Observations & Mean & Std. Dev. & Minimum & Maximum \\
\hline$P_{t}$ & 4058 & 1283.053 & 749.645 & 263.000 & 4407.010 \\
\hline$Y_{t}$ & 4057 & $9.70 \mathrm{E}-05$ & 0.008 & -0.046 & 0.042 \\
\hline$v_{t}$ & 4058 & $6.83 \mathrm{E}+08$ & $1.02 \mathrm{E}+09$ & 0.000 & $9.69 \mathrm{E}+09$ \\
\hline$V_{t}$ & 4057 & 0.098 & 0.086 & 0.000 & 1.169 \\
\hline
\end{tabular}

\subsection{Stationary Test}

To establish GARCH family models to simulate index return fluctuation, sequence $\left\{Y_{t}\right\}$ must be stationary. In the ADF test, the t statistic value is -59.8395 , less than the critical value under $1 \%$ significance level, and the corresponding $P$ value is close to 0 . Therefore, we can reject the null hypothesis of unit root, and the GARCH family models is established based on the stationary daily index return series, to simulate the fluctuation of the return rate.

\subsection{ARCH effect test of the residual}

To further test the ARCH effect of the residual, we first examine the autocorrelation of the sequence $\left\{Y_{t}\right\}$, and find that the yield series has significant autocorrelation and partial autocorrelation from the first order. Therefore, we build mean equation of return rate with form of ARMA. The ARMA $(p$, $q$ ) model contains autoregressive terms and moving averages terms, the equation is as follows:

$$
Y_{t}=\sum_{i=1}^{p} \gamma_{i} Y_{t-i}+\sum_{j=1}^{q} \varphi_{j} \varepsilon_{t-j}+\varepsilon_{t}
$$

In equation (1), the existence of autocorrelation causes the stock index volatility to be affected by the previous volatility, and $\varepsilon_{t-j}$ is the lagged term of the perturbation term of the mean equation, which is used to measure the previous volatility information.

According to the Akaike Information Criterion (AIC), the Schwartz Information Criterion (SIC) and the principle of parsimony, we determine $\mathrm{AR}(2)$ as autoregressive model of the construction industry return rate series, and the mean equation can be expressed as:

$$
Y_{t}=\gamma_{0}+\gamma_{1} Y_{t-1}+\gamma_{2} Y_{t-2}+\varepsilon_{t}
$$

We examine residuals of mean equations with conditional heteroscedasticity ARCH-LM test, when the lagged order is 5 , the $\mathrm{P}$ value of the residual series is still far less than the significance level of $1 \%$, which indicates that there is a high-order ARCH effect in the series. Therefore, we build GARCH family models to replace the high-order ARCH model. 
Table 4. ARCH effect test of the residual

\begin{tabular}{ccccc}
\hline & F-statistic & Prob. F(5,4045) & Obs*R-squared & Prob. Chi-Square(5) \\
\hline Test value & 127.7251 & 0.0000 & 552.3654 & 0.0000 \\
\hline
\end{tabular}

\section{Construction of GARCH family models}

\subsection{Construction of GARCH(1,1)model}

Given that the GARCH(1,1) model can explain the volatility clustering of financial sequences to a certain degree, it can also explain the phenomenon of obvious peak and fat tail of financial sequences ${ }^{[8]}$. Combining the statistical characteristics of the sample and taking into account the modeling conciseness and overall significance, we first establish the GARCH $(1,1)$ model in the industry analysis. In the generalized autoregressive conditional heteroscedasticity model, two different points should be considered: conditional mean equation and conditional variance equation. By introducing industry trading volume as a control variable in the variance equation, and taking the construction industry as an example, we can establish a $\operatorname{GARCH}(1,1)$ model whose mean equation is same to equation (2), and the variance equation is:

$$
h_{t}=\alpha_{0}+\alpha_{1} \varepsilon_{t-1}^{2}+\beta_{1} h_{t-1}+V_{t}+\sum_{i=1}^{4} \xi_{i} D_{i} .
$$

In equation (3), $h_{t}$ is the conditional variance of the random disturbance term in equation (2) at time $t$, and $h_{t}$ depends on the residual square $\varepsilon_{t-1}^{2}$ at time $t-1$ period.

\subsection{Construction of TARCH(1,1)model}

In practice, many stock returns have a leverage effect, which means, there is a strong negative correlation between current earnings and future fluctuations. When the returns increase, the volatility decreases and vice versa. The threshold ARCH model (TARCH) proposed by Zakoian, is based on the ARCH model, and introduces a dummy variable as a threshold, which can effectively describe the asymmetric effect of the volatility [9]. Ma Guoteng and Zhao Yan believe that $\operatorname{TARCH}(1,1)$ can eliminate conditional heteroscedasticity better when analyzing the characteristics of the fluctuation of the Hushen 300 Index return volatility ${ }^{[10]}$. In order to identify the leverage effect, we also consider constructing TARCH process to reveal the asymmetric effect on stock returns arised from different types of events. The mean equation of TARCH process is the same as equation (2). The conditional variance equation can be expressed as:

$$
h_{t}=\alpha_{0}+\alpha_{1} \varepsilon_{t-1}^{2}+\lambda_{1} d_{t-1} \varepsilon_{t-1}^{2}+\beta_{1} h_{t-1}+V_{t}+\sum_{i=1}^{4} \xi_{i} D_{i}
$$

Where $d_{t-1}$ is a dummy variable as a threshold. When $\varepsilon_{t-1}<0, d_{t-1}=1$; when $\varepsilon_{t-1} \geq 0, d_{t-1}=0$. Using dummy variables to set thresholds can distinguish effects of bad and good news on conditional volatility.

\subsection{Construction of EGARCH(1,1)model}

Nelson proposed another model EGARCH, whose conditional variance is a linear logarithm form [11]. It can reflect the effect of information asymmetry. Because the GARCH model has a strong non-negative constraint on coefficient parameters, it limits the flexibility of conditional variance, Jiang Xiangcheng et al. consider that it is ideal to use EGARCH $(1,1)$ model as a reference for the prediction of Shanghai and Shenzhen Stock Exchange ${ }^{[12]}$. Therefore, based on the mean equation $\mathrm{AR}(2)$, we build the conditional variance equation of the construction industry as follows: 


$$
\ln \left(h_{t}\right)=\alpha_{0}+\alpha_{1}\left(\frac{\varepsilon_{t-1}}{h_{t-1}^{0.5}}\right)+\lambda_{1}\left|\frac{\varepsilon_{t-1}}{h_{t-1}^{0.5}}\right|+\beta_{1} \ln \left(h_{t-1}\right)+V_{t}+\sum_{i=1}^{4} \xi_{i} D_{i}
$$

In the analysis of other industries, we only need to determine the form of the mean equation and bring the relevant data of the sample industry into equations (3), (4) and (5), and then we can establish GARCH models for different industries.

\section{Empirical results analysis}

We use AIC and the principle of parsimony to determine the mean equation of the stock price volatility in the sample industry. When the variance equations are $\operatorname{GARCH}(1,1), \operatorname{TARCH}(1,1)$ and EGARCH $(1,1)$ respectively, the estimated results for each coefficient are as Table 5 shows.

From the estimation results, GARCH terms and ARCH terms can pass the $1 \%$ significance level test in any industry, indicating GARCH $(1,1)$ model, TARCH $(1,1)$ model and EGARCH $(1,1)$ model can fit the sample industry stock returns well. Moreover, the ARCH-LM test shows that the P value of the LM statistic is significantly larger than the critical value of the $1 \%$ significance level, which proves that the ARCH effect does not exist in the residual series, and the information in the residual has been extracted cleanly.

The estimated coefficients of $d_{t-1} \varepsilon_{t-1}{ }^{2}$ in the $\operatorname{TARCH}(1,1)$ model for construction, manufacturing, and real estate industries are $0.0155,0.0490$ and 0.0241 respectively, and all of them pass the $10 \%$ significance level test, proving that there is indeed a significant asymmetry in the stock prices volatility of industries with relatively strong periodicity. The significance of the TARCH model parameter is generally better than the ordinary GARCH model. The fitting effect of TARCH is better.

Table 5. Estimated results of construction, manufacturing, and real estate industries based on the GARCH family models

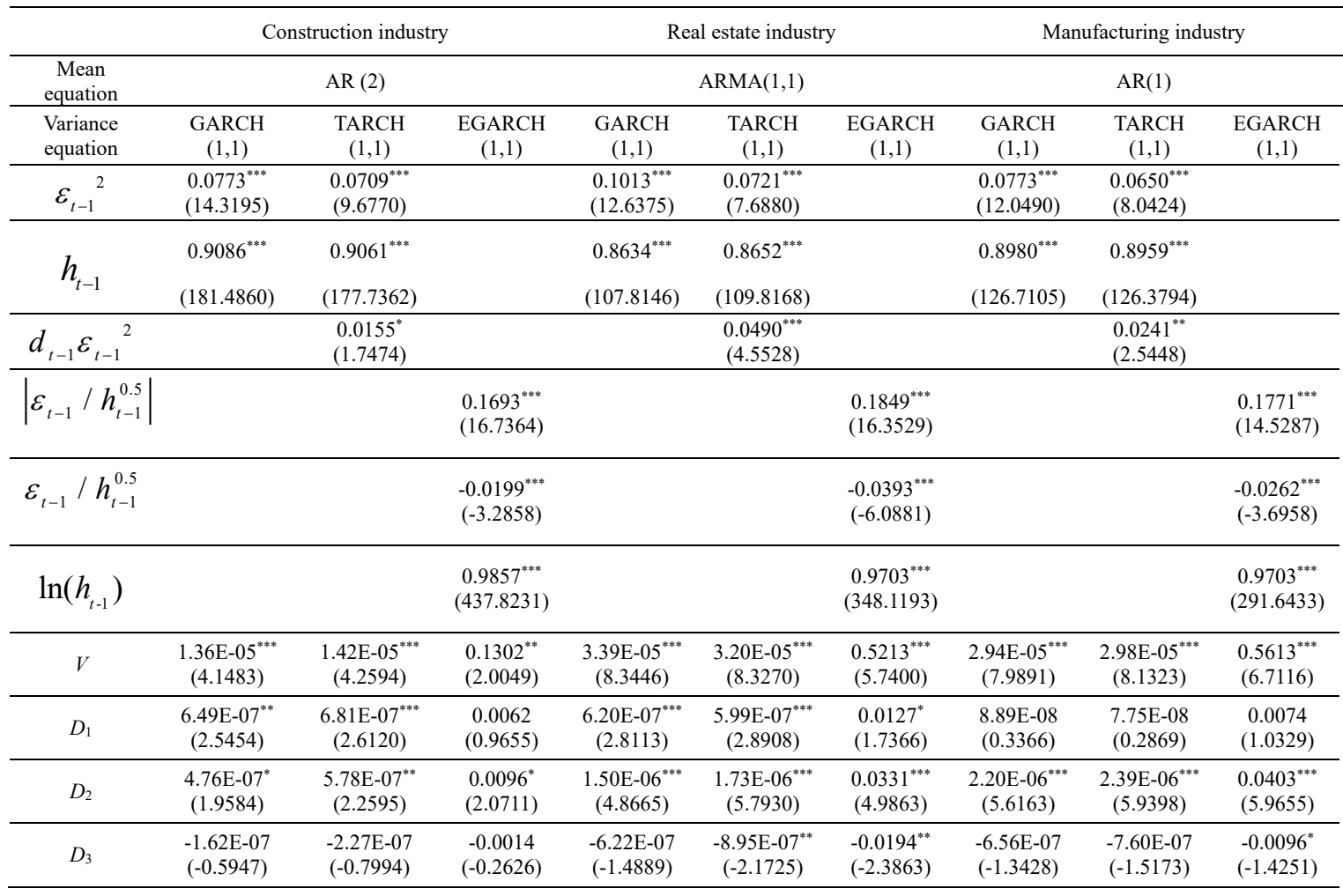


Table 5, cont. Estimated results of construction, manufacturing, and real estate industries based on the GARCH family models

\begin{tabular}{ccccccccccc}
\hline$D_{4}$ & $\begin{array}{c}-4.84 \mathrm{E}-07^{*} \\
(-1.9336)\end{array}$ & $\begin{array}{c}-4.60 \mathrm{E}-07^{*} \\
(-1.7707)\end{array}$ & $\begin{array}{c}-0.0016 \\
(-0.3001)\end{array}$ & $\begin{array}{c}-5.22 \mathrm{E}-07 \\
(-1.4311)\end{array}$ & $\begin{array}{c}-3.81 \mathrm{E}-07 \\
(-1.0624)\end{array}$ & $\begin{array}{c}0.0114 \\
(1.4344)\end{array}$ & $\begin{array}{c}-7.67 \mathrm{E}-07^{* *} \\
(-1.7726)\end{array}$ & $\begin{array}{c}-7.63 \mathrm{E}-07^{* *} \\
(-1.7191)\end{array}$ & $\begin{array}{c}-0.0104 \\
(-0.2075)\end{array}$ \\
\hline AIC & -6.9348 & -6.9348 & -6.9362 & -7.1119 & -7.1147 & -7.1175 & -6.7455 & -6.7460 & -6.7436 \\
\hline$R^{2}$ & 0.0043 & 0.0043 & 0.0043 & 0.0067 & 0.0065 & 0.0062 & 0.0028 & 0.0028 & 0.0032 \\
\hline $\begin{array}{c}\text { Log } \\
\text { likelihood }\end{array}$ & 0.3113 & 14072.26 & 14075.17 & 14433.99 & 14440.54 & 14446.23 & 13690.81 & 13692.97 & 13688.00 \\
\hline
\end{tabular}

Note: The value of the $\mathrm{z}$ statistic is in brackets; *,** and *** indicate that the test statistic is significant at the levels of $10 \%, 5 \%$ and $1 \%$ respectively.

In the EGARCH(1,1) model, the estimated value of $\varepsilon_{t-1} / h_{t-1}^{0.5}$ passed the $5 \%$ significance level test in each representative industry (line 8 of Table 5), which further proves that asymmetry did exist in the stock price volatility for above industries during 2003-2017, echoing the judgment of the leverage effect on the Chinese stock market by Chen Langnan and Huang Jiekun ${ }^{[13]}$.

Taking the construction industry as an example, in the variance equation of the EGARCH model, the estimation result of the symmetry term $\left(\varepsilon_{t-1} / h_{t-1}^{0.5}\right)$ is $\alpha_{1}=-0.0199$ and significant, and the ARCH term $\left(\left|\varepsilon_{t-1} / h_{t-1}^{0.5}\right|\right)$ estimated result is $\lambda_{1}=0.1693$. This means that when there is good news, the construction industry index will be $\lambda_{1}+\alpha_{1}=0.1494$ times positively affected; when the same degree of bad news occurs, it will be $\lambda_{1}-\alpha_{1}=0.1892$ times negatively impacted, reflecting the "asymmetry" of the returns volatility, and the impact caused by bad news is $\left(\lambda_{1}-\alpha_{1}\right) /\left(\lambda_{1}+\alpha_{1}\right)=1.2664$ times than that caused by the same good news. Similarly, the asymmetry multiples of manufacturing and real estate industries are as high as 1.5398 and 1.3472, showing that manufacturing stock price volatility has a stronger leverage effect. This is because such industry is in recession, and the market reacts more strongly to bad news. In addition, the common feature of the dummy and control variable parameter estimated results in GARCH model and TARCH model is that the estimated value is small but significant, which is consistent with the results of Wan Hong and Lv Dehong ${ }^{[14]}$.

In the EGARCH model, the parameter estimations are much larger than that of GARCH and TARCH models. Therefore, we hold the view that the EGARCH model can better explain the economic significance of the parameters when the statistics figures are significant. EGARCH model can better reflect the impact of variations in QFII shareholding on the volatility of stock returns. When regarding control variable $V$ as zero, we can analyze the significance of the dummy variables in the EGARCH $(1,1)$ model of three industries respectively, to determine the impact of the QFII shareholding on the volatility of stock returns in these industries.

\subsection{Impact on construction industry stock returns volatility}

In the GARCH(1,1), TARCH $(1,1)$ and $\operatorname{EGARCH}(1,1)$ models, coefficients of $D_{1}$ and $D_{2}$ are positive, and coefficients of $D_{3}$ and $D_{4}$ are both negative. The parameters estimation of EGARCH model shows that the QFII shareholding did not play the expected "market stabilizer" role when the construction industry was in the growth phase, but intensified the volatility of stock returns. The possible reason is that at the beginning of the establishment of the QFII system, some related supporting policies and systems have not yet been established. Since 2012, the construction industry entered a maturity phase, QFII increased its shareholding ratio, but the effect of restraining the return volatility of the industry was not obvious. After the third and fourth expansion, the regression coefficient turned from positive to negative. However, due to the fact that the construction industry is already at a mature phase during this period, it is difficult for companies to maintain high profitability in the long-term, and because QFII has not increased their shareholdings in the industry for a long period of time, the effect of stabilizing fluctuations is not obvious. 


\subsection{Impact on Manufacturing Industry stock returns volatility}

The coefficients of $D_{1}$ and $D_{2}$ in the EGARCH model are positive and significant, indicating that the introduction of the QFII system in 2003 and the first expansion of the QFII quota in 2005 intensified the volatility of manufacturing stock returns. With the absolute decline in China's labor resources for the first time in 2012, the "demographic dividend" has disappeared. Under the pressure of rising labor costs and sustained fluctuations in the prices of raw materials, the manufacturing industry has entered a period of recession, and QFII has begun to reduce its shareholding. After the third expansion event significantly reduced the volatility, the fourth expansion slightly intensified the volatility. The reasons why QFII's impact on the yield rate is not stable are as follows: First, the industry's net profit margins decline in recession, only the performance of some well-growing listed companies is valued by the QFII. Second, on account of the weak QFII's influence, the demonstration effect is not apparent. Although QFII is constantly expanding its capacity, the total amount of China's stock market is also increasing in the same period, so QFII has no obvious effect on the stability of the stock market.

\subsection{Impact on Real estate Industry stock returns volatility}

The coefficients of $D_{1}$ and $D_{2}$ in the EGARCH model are positive, indicating that the initial introduction of the QFII system and the first quota expansion have intensified the volatility of the stock returns. Due to successive bull market irrational investment and financial crisis short-term speculation, especially in the expansion during 2005-2012, the volatility has become more evident. The last two expansions represented by $D_{3}$ and $D_{4}$ both inhibit the fluctuation of stock returns. Based on parameters, QFII has a stronger hamper effect on the real estate industry than others. Comparing the coefficients of $D_{3}$ and $D_{4}$ in the EGARCH model, we can obtain that after the fourth expansion, the marginal impact of stabilizing stock returns fluctuations by QFII has increased by $0.08 \%$. The real estate industry is a growing industry which is mainly focused by QFII after it entering the Chinese market. Compared with the first two industries, QFII has a more significant impact on the real estate stock returns. This, to a certain extent, shows that long-term major-holdings of growth industries are one of the prerequisites for QFII to better play its role in stabilizing stock price volatility.

In conclusion, there is a significant asymmetry in the volatility of the Chinese stock market. Regardless of the phase of the industry, QFII failed to stabilize the market when it first entered China because of the limited investment, the immature operating environment and the impact of the international financial crisis. After two expansions, QFII began to show its stabilizing effect on the fluctuations of relevant industry indices, especially for industries that have been in the growth phase for a long time, the impact of QFII on the fluctuation of the stock price of the industry was significantly stronger than that of other industries, and the stabilization effect was gradually increasing. According to the estimated result of the dummy variable in the EGARCH model reflecting the two subsequent expansion events, it can be seen that the fluctuations in the stock returns of the construction industry and the real estate industry decreased by 0.02 and 0.08 percentage points respectively compared with the third expansion, while because of production capacity surplus, the impact of QFII's stabilization is not obvious on the manufacturing industry.

\section{Conclusion}

Based on the perspective of industry life cycle, this paper builds GARCH, TARCH and EGARCH models respectively, and explores the impact of QFII shareholding tendency on the volatility of stock returns in construction, manufacturing and real estate industries during from 2003 to 2017. 
The research shows that: First, the leverage effect of stocks is significant in industries with strong periodicity, such as construction, manufacturing and real estate. The analysis of the influence of EGARCH model on QFII holdings has better explanatory power. Second, QFII's major-held positions tend to support industries in growth phase for a long period of time. When an industry transits from the growth phase to a mature or recession period, QFII shareholding strategy will also be adjusted accordingly. Third, QFII does not play a role in stabilizing growth industries' stock market performance in the initial period after expansion. Instead, it significantly aggravates the fluctuations. However, with the increase in the QFII investment quota, it plays an increasingly significant role in stabilizing volatility. Fourth, QFII has a stabilizing effect on the stock price volatility of industries that have been growing for a long period of time, compared to industries that have transited from growth to mature or from growth to recession.

With the construction of the "One Belt and One Road" initiative, the RMB's position in the global currency system will gradually increase, and the importance of the Chinese market to foreign institutional investors will be further highlighted. Continuing to deepen foreign exchange management reforms of QFII, and appropriately expanding QFII investment quotas will help improve the participants in the Chinese capital market, promote the cautious opening of capital projects, and force the transformation and upgrading for resources-oriented industries and overcapacity industries.

\section{Acknowledgement}

This research was financially supported by the Youth Project of National Social Science Foundation "Analysis of China's Potential Economic Growth Rate and Growth Factors from the Perspective of Supply- demand Equilibrium" (Grant NO. 16CJL011).

\section{References}

[1] Yi Dong, Min Gu, and Yandong Jia, New Characteristics of "Policy Effect" in China's Stock Market: Empirical Analysis from QFII, Finance \& Economics, vol.5, pp. 26-30, 2003.

[2] Nianxing $\mathrm{Xu}$, Shangyao $\mathrm{Yu}$, and Zhihong Yi, Institutional investors' flock behavior and stock price crash risk, Management World, vol.7, pp. 31-43, 2013.

[3] Yulei Rao, Junlin $\mathrm{Xu}$, Lixing Mei, and Min Liu, The Impact of QFII Shareholding on Stock Price Synchronicity, Journal of Industrial Engineering and Engineering Management, vol.27, pp. 202-208, 2013.

[4] Guoqi Liu, Application of Non-Linear GARCH Model in Forecasting China's Stock Market Volatilities, Statistical Research, vol.17, pp. 49-52, 2000.

[5] Xuebin Deng, Institutional Investors and Stock Price Volatility_—Take Social Security Fund and QFII for Example, HaiNan Finance, vol.2, pp. 8-11, 2009.

[6] Yang Zhao, The Influence of QFII to China Stock Market Volatility Analysis, Southwestern University of Finance and Economics, 2016.

[7] Conglai Fan and Jing Yuan, An Empirical Analysis on M\&A Performance of the Public Companies of the Growing, Mature and Declining Industries, China Industrial Economy, vol.8, pp. 65-72, 2002.

[8] Yang Luo, Guiyuan Yang, Research on Shanghai Stock Exchange Volatility Based on GARCH Model, Statistics \& Decision, vol.12, pp. 162-165, 2013. 
[9] Zakoian J M. Threshold heteroskedastic models, Journal of Economic Dynamics \& Control, vol.18, pp. 931-955, 1994.

[10]Guoteng Ma and Yan Zhao, An Empirical Analysis of the Return Volatility of the HuShen 300 Stock Index-Based on the TARCH Model, Economic Forum, vol.2, pp. 169-171, 2010.

[11]Nelson D B. Conditional Heteroskedasticity in Asset Returns: A New Approach, Econometrica, vol.59, pp. 347-370, 1991.

[12]Xiangcheng Jiang and Yamin Xiong, On Analysis of the Volatility of Chinese Stock Market Based on GARCH Model, Journal of Southwest China Normal University (Natural Science Edition), vol.42, pp. 115-119 2017.

[13]Langnan Chen and Jiekun Huang, An Empirical Study on the Asymmetry of Volatility in China's Stock Market, Journal of Financial Research, vol.5, pp. 67-73, 2002.

[14]Hong Wan, Dehong Lv, Influence of QFII System on the Volatility of Shanghai A Shares Market_-An Empirical Analysis Based on Data from 2002 to 2013, Review of Economic Research, vol.47, pp. 63-66, 2014. 